\title{
Entre escolhas e silêncios: a construção da memória de Gonçalves Dias como poeta nacional
}

\author{
Andréa Camila de Faria \\ Bolsista do Programa de Treinamento e Capacitação Técnica da FAPERJ
}

Um poema nacional?

Manuel Salgado Guimarães afirmava que lembrar significa, para o historiador, não apenas trazer algo novamente à lembrança e poder partilhá-lo, mas também poder ressignificá-lo sob as demandas de um novo tempo. Nesse sentido, a recordação, para o historiador, traria junto um exercício de crítica, como parte de um procedimento hermenêutico que nos obrigaria a pensar sobre as condições de produção da memória. Em suas palavras, "O trabalho da memória, todos sabemos, tende a sacralizar seus objetos, que, uma vez postos em altares, são naturalizados". ${ }^{1}$ E para ele, que estava pensando em Capistrano de Abreu "se construindo enquanto autor de história",

quando o objeto da recordação é um dos autores canônicos de nosso campo de trabalho, (...) a tarefa deve considerar igualmente esse processo de produção específica, que nos remete necessariamente à recepção de seus textos. Seus leitores desempenham papel ativo nesse trabalho de produção textual. ${ }^{2}$

Guardadas as devidas proporções, esta relação que ele estabelece para pensar Capistrano pode ser estendida para Gonçalves Dias, também um autor canônico, senão no campo da história, ao menos no das letras nacionais.

Nascido na cidade maranhense de Caxias em agosto de 1823, Gonçalves Dias quis 'fazer seu nome' e para isso buscou realizar seu projeto de tornar-se o maior poeta do Brasil. Alcançando seu objetivo, através do reconhecimento obtido já na publicação de sua primeira obra, como veremos adiante, sua 
imagem de ícone nacional foi aos pouco construída através da vinculação de sua vida e de sua obra à pátria. Uma vez posto no panteon nacional como representante do que era essencialmente 'brasileiro', sua memória foi sendo naturalizada e incorporada à memória coletiva nacional. E sem dúvida não há maior expressão dessa naturalização do que a difusão dos versos de sua famosa Canção do exílio.

Como afirma Maria Helena Rouanet, os versos "Nosso céu tem mais estrelas, / Nossas várzeas têm mais flores, / Nossos bosques têm mais vida,/ Nossas vidas mais amores" foram tão eficazes em proclamar a diferença entre o eu e o outro, o nacional e o estrangeiro - a polaridade norteadora da construção de identidade (nacionalidade) no romantismo - que além de serem reproduzidos por vários outros poetas românticos, acabaram se institucionalizando de vez na letra do Hino Nacional ${ }^{3}$.

Mas essa institucionalização torna-se curiosa se pensarmos que esse poema foi escrito em Coimbra, em julho de $1843^{4}$, quando Gonçalves Dias era ainda um jovem de 19 anos, distante de sua terra natal já há 4 anos. Aliás, quando nos referimos a sua terra natal precisamos deixar claro que não estamos nos referindo ao Brasil, esta unidade nacional tão evocada, mas a uma pequena partícula desse todo, ao Maranhão, ou antes, a Caxias, esta sim, sua 'terra natal'.

Ao partir para Coimbra em 1838 o jovem Gonçalves Dias não conhecia mais do que Caxias, o sítio de Boa Vista, onde nascera, e a capital da província, São Luiz. ${ }^{5}$ Uma parte do Maranhão era o máximo de 'Brasil' que ele conhecia. Aliás, o próprio poeta ao publicar sua Canção fez questão de ressaltar: "Quando eu compuz esta canção, ou como melhor se chame, tinha apenas visto algumas das Províncias do Norte do Brasil". Esta simples nota nos faz pensar que talvez aquele que é o poema nacional por excelência, conhecido nos quatro cantos do país, incessantemente reproduzido nos manuais didáticos, não seja exatamente 'nacional', mas antes, 'regional'. Afinal as tais palmeiras seriam as nossas conhecidas palmeiras imperiais do Jardim Botânico do Rio de Janeiro, importadas para o Brasil por D. João $\mathrm{VI}^{7}$, ou a nativa carnaúba, muito comum nas 'Províncias do Norte'? A maior parte das evidencias apontam para a segunda opção.

Não queremos com isso, contudo, retirar Gonçalves Dias de sua posição no panteon nacional. O que nos importa é problematizar essa figuração, 
entende-la como uma construção, como mais uma das muitas construções de memória que são responsáveis por criar uma identidade comum. Nesse caso, nos parece que a propagação de Canção do Exílio como poema nacional por excelência se deu sem que se levasse em conta o regionalismo que a produzira, ou antes, desconsiderando-se propositalmente essa característica a fim de torná-la um símbolo que bem representasse o sentimento nativista que se queria construir, nosso 'nacionalismo'. Nesse caso, sem que Gonçalves Dias planejasse, seu poema foi alçado ao posto de canção nacional e seu autor, por conseguinte, ao de cantor da pátria, de iniciador da literatura brasileira, numa construção de memória que merece, no mínimo, ser demarcada.

Entre escolhas e silêncios a criação de um brasileiro

As províncias do norte do Brasil foram as que mais tarde aderiram à independência do Império. Caxias, então chamada Aldeias Altas no Maranhão, foi a derradeira. A independência foi ali proclamada depois de uma luta sustentada com denodo por um bravo oficial português que ali se fizera forte. Isto teve lugar à (sic) $1^{\circ}$ de Agosto de 1823. Nasci a 10 de Agosto desse ano. ${ }^{8}$

Segundo Joël Candau não podemos recordar um acontecimento do passado sem que o futuro desse passado seja integrado à lembrança ${ }^{9}$, isto é, lembrar uma história nunca é recuperá-la sem as influências de seu futuro, pois "o tempo da lembrança não é o passado, mas 'o futuro já passado do passado" "10. Nesse sentido, toda recordação é, segundo o autor, tributária da natureza do acontecimento memorizado, do contexto passado desse acontecimento e também daquele momento de recordação. ${ }^{11}$ Em suas palavras,

O narrador parece colocar em ordem e tornar coerente os acontecimentos de sua vida que julga significativos no momento mesmo da narrativa: restituições, ajustes, invenções, modificações, simplificações, "sublimações”, esquematizações, esquecimentos, censuras, resistências, não ditos, recusas, "vida sonhada", ancoragens, interpretações e reinterpretações constituem a trama desse ato de memória que é 
sempre uma excelente ilustração das estratégias identitárias que operam em toda narrativa. ${ }^{12}$

Recuperar uma lembrança, especialmente uma lembrança autobiográfica é criar uma memória, uma identidade, e esse movimento nos permite vislumbrar algumas das estratégias de criação identitária, mesmo que nem sempre elas estejam perfeitamente às claras ou pareçam deliberadas.

No caso de Gonçalves Dias é sintomático que o poeta, ao escrever nota autobiográfica a pedido do francês Fedinand Denis, tenha relacionado diretamente seu nascimento ao 'nascimento' da pátria, na menção a consolidação da independência com a rendição do Maranhão em agosto de 1823. Está claro que para o menino que nascia a 10 de agosto daquele ano, o fato de que o país estava recém-saído de sua condição colonial e de que sua província natal resistira a essa metamorfose, não era questão importante, aliás, nada que não dissesse respeito aos cuidados maternos requisitados por um bebê recém-nascido devia importar.

Mas para o homem de letras que se consolidara já em 1846, quando da publicação de seus Primeiros Cantos, como o maior poeta do Brasil, membro do Instituto Histórico, parte ativa dos projetos de (re)construção da nação, estabelecer esta relação significava criar para si próprio uma identidade e uma origem singular. Nas palavras da biógrafa Lucia Miguel Pereira, a nota é:

importantíssima, pelo que diz, e pelo que omite. Mais ainda pelo que omite do que pelo que diz. Com efeito, ligando o seu nascimento aos sucessos políticos, patenteia Gonçalves Dias que foi profundamente marcado por eles. Que o fato de nascer com a independência da sua província influiu no seu feitio, na direção que imprimiu à sua obra. Do contrário não mencionaria a coincidência nessa concisa informação, em que mais nada adiantou sobre a sua vida particular. ${ }^{13}$

$\mathrm{Na}$ interpretação da biógrafa, em seu silêncio Gonçalves Dias deixava transparecer a inquietação de seu lugar social, de sua posição de filho natural de uma mãe mestiça e um pai português que resistira à independência do Brasil. Era o silêncio revelador de um 'estado d'alma'. ${ }^{14}$ Não nos cabe aqui aprofundar ou debater tal interpretação, embora deva se pensar que talvez 
sua condição de mestiço tenha pesado - positivamente, devo dizer - para sua identificação como ícone da nacionalidade brasileira. Mas seja como for, ao estabelecer esta relação, o poeta firmou para si um pertencimento e uma vinculação particular com sua pátria, numa imagem que ajudou a perpetuar o seu nome junto à memória nacional.

Para Marcia de Almeida Gonçalves, ao estabelecer esta relação, Gonçalves Dias, mais do que um pertencimento, firmava um compromisso de representar por meio de sua vida particular - e aqui entendemos também por meio de sua obra - a comunidade imaginada, sentida e significada como nação. ${ }^{15}$

De alguma maneira podemos dizer que Gonçalves Dias decidira proclamar-se como brasileiro desde o nascimento, identificando-se ao Brasil cuja imagem ajudava a divulgar e (re)construir, num exercício onde o presente e o futuro pesavam decisivamente sobre a memória do passado. Ele 'era brasileiro' desde o nascimento, mesmo que 'ser brasileiro' nesse momento ainda fosse algo em construção.

Operações complexas, a reconstrução de um passado e a conseqüente construção de sua memória, demonstram alguns dos objetivos escondidos atrás desses movimentos. Movimentos que, no caso das narrativas pessoais, buscam tornar estável, verossímil e previsível os projetos que norteiam ou nortearam a vida daquele indivíduo. Nesse sentido, como afirma Candau, "todo aquele que recorda domestica o passado e, sobretudo, dele se apropria, incorpora e coloca sua marca em uma espécie de selo memorial que atua como significante da identidade" ${ }^{16}$. Assim ao relacionar diretamente seu nascimento ao nascimento da pátria, Gonçalves Dias procurou criar para si uma identidade que o vinculava diretamente ao seu objetivo, ao seu projeto de vida.

Nesse sentido torna-se importante para nós pensarmos as noções de 'projeto e campo de possibilidades' tal como entendidas pelo antropólogo Gilberto Velho. Para ele 'projeto' deve ser entendido como uma conduta organizada para atingir finalidades específicas e 'campo de possibilidades' é uma dimensão sociocultural, um espaço para formulação e implementação de projetos, tendo em mente que os projetos, assim como as pessoas, mudam, ou antes, que as pessoas mudam através de seus projetos. Em suas palavras,

As trajetórias dos indivíduos ganham consistência a partir do delineamento mais ou menos elaborado de projetos com objetivos 
específicos. A viabilidade de suas realizações vai depender do jogo e interação com outros projetos individuais ou coletivos, da natureza e da dinâmica do campo de possibilidades. ${ }^{17}$

O projeto de Gonçalves Dias era 'fazer brilhar' sua carreira literária e criar para si um nome que o tornasse reconhecido como poeta. Suas cartas demonstram, especialmente em sua juventude em Coimbra e no momento do seu retorno ao Brasil, a insegurança e a instabilidade que cercavam este projeto. Em 22 de abril de 1845, por exemplo, pouco depois de chegar a Caxias, vindo de Portugal, ele escrevia ao amigo Alexandre Teófilo: "Futuro?! lá se vai com o resto dos meus doidos projetos. Poesia?! já lhe perdi o amor e nenhum outro tenho para o substituir - Glória?! 'o meu destino é de a cobiçar do mais intimo d'alma, e de morrer sem a ter provado" ${ }^{18}$ ", ${ }^{19}$

Desconsideradas as marcas da melancolia que transparecia sempre que o poeta tratava de seus objetivos para o futuro, está claro que havia em seu projeto um objetivo de alcançar glória, renome, naquilo que ele julgava ser o seu destino, a poesia. Essa melancolia, que Lúcia Miguel Pereira ${ }^{20}$ identifica como marca de sua sensibilidade romântica, não deve mascarar, contudo, as tramas de suas realizações. Como dito por Gilberto Velho, a realização de projetos depende das interações sociais e das dinâmicas dos campos de possibilidade, e Gonçalves Dias parecia ter consciência disso, afinal soube colocar acima de seu orgulho a vontade de realizar seu objetivo, permitindo assim que as relações sociais fossem determinantes na consolidação de sua carreira literária.

Prova disso é que comentando sobre sua vida em Coimbra, afirmou ao amigo Alexandre Teófilo em carta de $1^{\circ}$ de maio de 1845 :

Triste foi minha vida em Coimbra - que é triste viver fora da pátria, subir degraus alheios - e por esmola sentar-se à mesa estranha. Essa mesa era de amigos... embora! O pão era alheio - era o pão da piedade - era a sorte do mendigo. Compaixão! É um têrmo de expressão incompreensível - não a quero.

Mas ser desconhecido - ou mal conhecido, mas sentir dores d'alma, mas viver e morrer sem nome, sonhar de tormentos e viver deles - é mais triste ainda. ${ }^{21}$ 
Para ‘fazer seu nome’ Gonçalves Dias embarcou, a 14 de junho de 1846, de S. Luiz do Maranhão para o Rio de Janeiro, planejando publicar seus Primeiros Cantos e arrumar um bom emprego que lhe permitisse seu sustento. Esta viagem foi o resultado de suas sociabilidades, afinal, sabendo que o amigo não tinha dinheiro para pagar a passagem do vapor que fazia o transporte entre as províncias, Alexandre Teófilo intercedeu junto ao vice-presidente do Maranhão, Ângelo Carlos Muniz, para que fosse concedida a Gonçalves Dias uma 'passagem de Estado' no navio Imperador. ${ }^{22}$ E assim foi feito.

Chegando ao Rio, aos 23 anos de idade, seu maior interesse era fazer brilhar sua carreira literária. Para isso, além de providenciar a publicação dos Primeiros Cantos e tentar a encenação de seu drama Beatriz de Cenci, passava horas a estudar na Biblioteca Pública. Dizia que sua vida literária seria "como os dias nos pólos, isto é, infinitamente pequena", por isso queria fazê-la "a mais brilhante possível". ${ }^{23}$

Mas Gonçalves Dias viera também buscar um emprego público, intuito para o qual contava ele com cartas de recomendação arranjadas durante o tempo que passara no Maranhão. As tais cartas, conseguidas por José Mamede Alves Ferreira e José Joaquim Ferreira Vale ${ }^{24}$, se não alcançaram seu objetivo imediato, como podemos supor por seu comentário em carta de 27 de agosto de 1846 - "Perguntas-me como fui recebido?! - bem; cartas de recomendação não servem se não de apoquentação; e fazer e receber visitas - nada mais. Ora eu tenho mais que fazer" 25 -, serviram certamente para alarga-lhe o círculo de sociabilidade.

Como nos mostra Marco Morel, as ruas da capital imperial eram, em meados do século XIX, locus privilegiado do fazer político, mesmo para aqueles que não interferiam diretamente nas decisões do poder. Em suas palavras, "as ruas da Cidade-Corte eram a cena de poder, ponto essencial para a organização da nacionalidade que se elaborava" ${ }^{26}$. Nesse sentido havia, ainda segundo Morel, por um lado, um movimento de expansão do centro sobre as periferias nacionais, mas por outro, um movimento contrário, de ocupação dos espaços públicos do centro do Império por agentes oriundos das províncias. Neste último caso, eles poderiam atuar como intermediários, trazendo demandas de seus locais de origem e também agindo como elos da centralização homogeneizadora nacional. ${ }^{27}$ 
Fosse como fosse, o Rio de Janeiro apresentava-se como o destino de todos aqueles que desejavam construir um nome de alcance nacional, tanto nas letras quanto na política, e era por saber disso que Gonçalves Dias comentara com sua comadre, Maria Luiza Leal Vale, esposa do Teófilo, em carta de $1^{\circ}$ de outubro de 1846 , que a prova de que era poeta era que estava no $\mathrm{Rio}^{28}$, afinal qual o melhor lugar para 'fazer brilhar sua estrela' do que o centro de efervescência cultural do Império?

E de fato seu objetivo fora alcançado já com a publicação de seus Primeiros Cantos, mas esse reconhecimento, que sem dúvida se deve ao seu valor literário e a inovação provocada no campo da poesia romântica indianista, merece ser melhor problematizado. O livro saíra à luz em fins de 1846 e em 23 de janeiro de 1847, pouco mais de um ano após sua chegada ao Rio de Janeiro, o poeta escrevia ao amigo Teófilo: "Os meus Primeiros Cantos saíram a luz, têm me sido gabado em particular, o que de certo nada quer dizer; a gazeta oficial prometeu falar neles - assim como alguns outros, e até agora nada de nôvo. Speranza mi sustiene". ${ }^{29}$

A publicação, que viera a lume resguardada de correlações políticas, foi efetuada e circulava com a ajuda da interferência de seus amigos, como podemos notar a partir da carta de 27 de agosto de 1846:

Como sabes, vim de lá com intenção de imprimir o meu volume de Poesias na Imprensa do Inácio; aqui porém me disseram que talvez eu me fôsse criar prevenções contra mim imprimindo a minha primeira obra em uma Imprensa de partido; achei que havia nisto um fundo de razão e desisti do meu proposto. O Serra falou com o Laemmert, e êle prestou-se prontamente - está já no prelo; (...) - tem sofrido alguma demora porque o Laemmert meteu-se agora em imprimir folhinhas. ${ }^{30}$

O trecho transcrito deixa claro que foi por intermédio de Serra que Gonçalves Dias chegou ao Laemmert, mas as 'ajudas' iriam muito além disso. Segundo ele, um colega de Teófilo no Colégio do José Pedro e que fora seu companheiro durante a viagem para o Rio, a quem ele chama apenas de Sousa, comprometera-se em lhe arranjar pelo menos 100 assinaturas para a sua obra em S. Paulo, com outros amigos, como o já citado Mamede, conseguira outras tantas. 
Não nos cabe discutir o talento de Gonçalves Dias. Mas será que o poeta receberia o mesmo reconhecimento se seus amigos não tivessem se empenhado em divulgar seu trabalho? Será que ele seria tão aclamado se seu livro não tivesse chegado às mãos de Alexandre Herculano, impressionando-o a tal ponto de escrever um artigo exaltando a poesia de Gonçalves Dias e estabelecendo o fim da história literária portuguesa e o nascimento da brasileira? Parece-nos que não.

No artigo em questão, intitulado Futuro Literário de Portugal e do Brasil, publicado por Alexandre Herculano no tomo 7 da Revista Universal Lisboense, anos de 1847-1848, o escritor português afirmava:

Nós somos hoje o hilota embriagado, que se punha defronte da mesa nas filiais de Esparta, para servir de lição de sobriedade aos mancebos. O Brasil é a moderna Esparta, de que Portugal é a moderna Helos. Estas amarguradas cogitações surgiram-me na alma com a leitura de um livro impresso o ano passado no Rio de Janeiro, e intitulado: Primeiros Cantos: poesias por A. Gonçalves Dias. Naquele país de esperanças, cheio de viço e de vida, há um ruído de lavor íntimo, que soa tristemente cá, nesta terra onde tudo se acaba. A mocidade, despregando o estandarte da civilização, prepara-se para os seus graves destinos pela cultura das letras; arroteia os campos da inteligência; aspira as harmonias dessa natureza possante que a cerca; concentra num foco todos os raios vivificantes do formoso céu, que a alumina; prova forças enfim para algum dia renovar pelas idéias a sociedade, quando passar a geração dos homens práticos $e$ positivos, raça que lá deve predominar ainda; porque a sociedade brasileira, vergôntea separada há tão pouco da carcomida árvore portuguesa, ainda necessariamente conserva uma parte do velho cepo. Possa o renovo dessa vergôntea, transplantada da Europa para entre os trópicos, prosperar e viver uma bem longa vida, e não decair tão cedo como nós decaímos! $!^{31}$

E ainda ponderava que os Primeiros Cantos eram "inspiração de um grande poeta" e que o poema Seus Olhos eram as composições mais mimosas que já havia lido. ${ }^{32}$ 
$\mathrm{O}$ artigo de Herculano chegou às mãos de Gonçalves Dias através de seu amigo português Gomes de Amorim, que o transcreveu e enviou para o Brasil na certeza de que os escrito surpreenderia e em muito alegraria o poeta maranhense. Os meios que levaram os Primeiros Cantos às mãos do ilustre letrado português, infelizmente nos são desconhecidos, talvez tenha influído para isso as sociabilidades portuguesas de Gonçalves Dias, mas o que é certo é que sua repercussão foi de grande importância na vida do jovem poeta. Nesse sentido, José Henrique de Paula Borralho, afirma que

A repercussão do artigo de Alexandre Herculano nos jornais do império foi imediata e pesou decisivamente para a visibilidade e dizibilidade do cantor timbirense e de sua utilização pelo império brasileiro dentro do projeto criador da nação. ${ }^{33}$

Num momento em que a nação se construía e se firmava receber a declaração de independência literária pelas mãos de um dos mais aclamados homens de letras da antiga metrópole certamente que se revestia de um aspecto mais do que simbólico, pois era também político. Com a exaltação de Gonçalves Dias feita por Herculano, o Império Brasileiro não era mais apenas independente politicamente, ganhara o aval para ser autônomo em sua literatura e história, e não seriam justamente essas duas esferas entre as principais responsáveis pela construção da nação?

Gonçalves Dias parecia ter plena consciência da importância que essa ‘aprovação’ possuía, prova disso é que ao organizar em 1857 uma publicação que reunia seus Primeiros, Segundos e Últimos Cantos - intitulada Cantos precedeu-o pelo artigo de Herculano, num claro recurso de (re)afirmação de sua obra e de sua imagem. No prólogo da edição ele afirmou:

A colecção de poezias, que agora reimprimo, vae illustrada com algumas linhas de A. Herculano, a que devo a maior satisfação que tenho ate hoje experimentado na minha vida litteraria.

Merecer a critica de A. Herculano, já eu consideraria como bastante honroso para mim; uma simples mensão do meo primeiro volume, rubricada com seo nome, desejava-o de certo; mas esperal-o, seria da minha parte demasiada vaidade. 
Ora, em vez da critica inflexível, que eu devera, mas não ousava receiar; em vez da simples noticia do apparecimento de um volume, que não seria de todo ruim, pois que teria merecido occupar a sua attenção; o ilustre escriptor poz por alguns momentos de parte a severidade que tem direito de usar para com todos, quando é tão severo para consigo mesmo, e, benevolamente indulgente, dirigio me algumas linhas, que me fiserão comprehender quão alto eu reputava a sua gloria, na plenitude de contentamento, de que as suas palavras me deixarão possuido. ${ }^{34}$

Gonçalves Dias ia assim firmando sua imagem de literato, mas mais do que isso, firmava sua imagem de poeta nacional, criando e recriando sua memória a cada novo escrito ou publicação, fixando seu nome na memória da nação.

De acordo com Joël Candau, “'fazer o nome’ é agir para a posteridade, ter a esperança estéril de não desaparecer no esquecimento" ${ }^{35}$, e essa busca requer o esforço de fazer escolhas, de jogar luz sobre os aspectos que se quer exaltados e jogar na penumbra aqueles que podem dificultar seu 'sucesso'. Nesse sentido é curioso pensar que nessa mesma edição dos Cantos, onde procurou dar destaque às palavras de Herculano sobre sua obra e sobre futuro da literatura brasileira, Gonçalves Dias tenha deixado de republicar a nota que pontuava a famosa Canção do Exílio como fruto da inspiração de um jovem que quase nada conhecia de Brasil, o que, como já dissemos, acabava insinuando ao poema uma forte marca de exaltação regional.

Entre o que foi dito e o que foi silenciado, outro ponto merece destaque na trajetória de Gonçalves Dias, a publicação de Meditação. Poema em prosa, fragmentário, escrito entre junho de 1845 e maio de $1846^{36}$, Meditação é considerada obra de transição entre sua atividade inteiramente poética e o impulso que o levaria à história e a etnografia. Para Antonio Candido ${ }^{37}$ é uma das obras de maior expressão política da primeira fase romântica, principalmente por tocar no melindroso assunto da escravidão, algo ainda incomum naquele momento.

Construída na forma de um diálogo entre um jovem e um ancião, o texto apresenta ao leitor todos os vícios de uma nação que se queria grande e virtuosa, mas, que segundo o ancião, estava destinada ao fracasso por ter suas bases cravadas sobre a escravidão. O jovem busca o Brasil e o ancião se 
encarrega de apresentá-lo, numa narrativa que faz duras críticas à organização política e social do país. Nesse jogo textual, Gonçalves Dias personifica ao mesmo tempo os dois lados, o novo e o velho, transmitindo através de cada um deles a sua 'visão de mundo'.

Dizendo estar diante de um grande império já que "tão grande espaço me parece que encerra" ${ }^{38}$, o jovem apresenta, então, a sua visão, admirando a natureza que se apresenta aos seus olhos, como ao descrever o céu que parece refletir o "sorriso benévolo e carinhoso do Criador"39, até que se depara com a "horrível maldição" que passa de pais para filhos, a escravidão. É nesse momento então que ele descreve a sociedade brasileira:

E sobre essa terra mimosa, por baixo dessas árvores colossais - vejo milhares de homens - de fisionomias discordes, de cor vária, e de caracteres diferentes.

E esses homens formam círculos concêntricos, como os que a pedra produz caindo no meio das águas plácidas de um lago.

$\mathrm{E}$ os que formam os círculos externos têm maneiras submissas e respeitosas são de cor preta: - e os outros, que são como um punhado de homens, formando o centro de todos os círculos, têm maneiras senhoris e arrogantes: - são de cor branca.

E os homens de cor preta têm as mãos presas em longas correntes de ferro, cujos anéis vão de uns a outros - eternos como a maldição que passa de pais a filhos! ${ }^{40}$

Círculos concêntricos liderados por um punhado de homens arrogantes enquanto uma maioria vivia submissa sob o peso de uma maldição, era assim que Gonçalves Dias enxergava a sociedade brasileira. Sem dúvida, apresentar assim a sociedade de uma nação em processo de consolidação era uma ousadia para alguém que a essa época sequer havia publicado seus Primeiros Cantos.

Mas ele ia além. Apontava claramente a escravidão como um fator de atraso ao desenvolvimento do país:

E nessas cidades, vilas e aldeias, nos seus cais, praças e chafarizes - vi somente - escravos! 
E à porta ou no interior dessas casas mal construídas e nesses palácios sem elegância - escravos!

E no adro ou debaixo das naves dos templos - de costas para as imagens sagradas, sem temor, como sem respeito - escravos!

E nas jangadas mal tecidas - e nas canoas de um só toro de madeira - escravos; - e por toda a parte - escravos!!...

Por isso o estrangeiro que chega a algum porto do vasto império - consulta de novo a sua derrota e observa atentamente os astros porque julga que um vento inimigo o levou às costas d'África.

E conhece por fim que está no Brasil - na terra da liberdade, na terra ataviada de primores e esclarecida por um céu estrelado e magnífico! Mas grande parte da sua população é escrava - mas a sua riqueza consiste nos escravos - mas o sorriso - o deleite do comerciante - do seu agrícola - e o alimento de todos os seus habitantes é comprado à custa do sangue escravo!

E nos lábios do estrangeiro, que aporta no Brasil, desponta um sorriso irônico e despeitoso - e ele diz consigo, que a terra - da escravidão - não pode durar muito; porque ele é crente, e sabe que os homens são feitos do mesmo barro - sujeitos às mesmas dores e às mesmas necessidades. ${ }^{41}$

E Gonçalves Dias tinha consciência de que a obra tratava de aspectos polêmicos do Império, tanto que quando tencionava publicá-la no periódico maranhense O Arquivo, ainda em 1846, remeteu a Alexandre Teófilo o segundo capítulo e por carta recomendou-lhe: "cortem sem dó - o que julgarem mau - ou 'arriscado de se imprimir"'"42. ${ }^{43}$ Mas a publicação não foi levada a cabo nesta época, talvez porque Teófilo julgasse uma publicação tão polêmica como imprópria para um momento em que o poeta ainda buscava reconhecimento e um emprego na Corte. De fato, se considerarmos que o momento era de debates e pressões inglesas para o fim do tráfico, as críticas de um jovem poeta que ainda tentava 'fazer brilhar sua estrela' certamente que poderiam lhe causar grandes dificuldades em alcançar seu intento.

Mas em 1849, num momento em que já havia alcançado determinado posicionamento profissional, e era um dos editores da revista Guanabara, ao 
lado de Manuel Araújo Porto Alegre e Joaquim Manuel de Macedo, o poeta decidiu então publicá-la, sem deixar de reconhecer seu caráter polêmico.

Infelizmente não conseguimos apurar qual foi à recepção do público letrado do Império à obra na época em que foi publicada, mas certamente seu conteúdo como podemos perceber, justificava a precaução de Teófilo quanto a sua publicação. Parece-nos estranho, no entanto, que ela tenha ficado 'esquecida' com o passar do tempo, quase não sendo mencionada pelos autores que frisam a colaboração de Gonçalves Dias à literatura brasileira, ficando restrita apenas aos que se aprofundaram em sua produção.

Numa obra com tal valor político, o mais natural seria que ficasse registrada como uma das principais contribuições do poeta, principalmente por ter sido pioneira no questionamento do sistema escravista, valor que será mais tarde tão elogiado em autores como Castro Alves. Por que então, Meditação teve sua 'fama' suplantada pelos versos de Canção do exílio ou de I-Juca Pirama? A qualidade literária não parece ser justificativa plausível, nos levando a suspeitar que esse esquecimento tenha sido condicionado pela vitória do próprio projeto de construção da nacionalidade brasileira de que Gonçalves Dias fez parte, afinal não era interessante aos dirigentes desse projeto vincular a nação aos problemas que nela se enraizavam, era mais vantajoso relacioná-la à exuberância da natureza e mesmo a uma origem indígena que levasse à valorização dos ideais de coragem e de conservação das tradições.

Nesse sentido, parece-nos que entre o poeta questionador e o romântico exaltador da natureza e dos primitivos 'brasileiros', venceu a segunda imagem, sendo a preferida por aqueles que ajudavam a formar a nossa nacionalidade. Um poeta romântico indianista contribuía muito mais para o amalgama da sociedade do que um jovem escritor politicamente exaltado.

Nesse sentido, o silêncio da crítica literária em relação à obra, tanto à época de sua publicação como posteriormente, parece indicar, como nos confirma Wilton José Marques que de alguma forma houve uma leitura reducionista do projeto literário de Gonçalves Dias, onde a crítica

procurou enfatizar, em detrimento do conjunto da obra literária, o caráter nacionalista dos poemas americanos, insistindo em rotular o poeta maranhense apenas e tão somente como o "cantor dos índios" ou ainda como o autor da "Canção do exílio". ${ }^{44}$ 
Estamos considerando aqui esse silêncio em torno de Meditação como um recurso narrativo, isto é, como um dos muitos recursos de que se lança mão no processo de elaboração de uma memória, mesmo que nesse caso, esse silêncio e essa construção de memória, não tenham sido plenamente determinados por Gonçalves Dias.

Mas ao pensarmos isso somos forçosamente direcionados a pensar nos meios pelos quais a memória de Gonçalves Dias, criada por ele ou não, se fixou e se transmitiu ao longo dos anos, especialmente após a sua morte. Nesse caso, parece-nos claro que os textos biográficos sobre o poeta foram determinantes em fixar sua memória/identidade de 'poeta nacional'.

Para Joël Candau o trabalho da memória nunca é um ato individual. Em suas palavras,

A forma do relato, que especifica o ato de rememoração, "se ajusta imediatamente às condições coletivas de sua expressão", o sentimento do passado se modifica em função da sociedade. (...) Muitas de nossas lembranças existem porque encontramos eco a elas, observação que conduziu Halbwachs a elaborar a noção de "quadros sociais da memória”. Por isso, é um tecido memorial coletivo que vai alimentar o sentimento de identidade. ${ }^{45}$

Nesse sentido está claro para nós que se Gonçalves Dias se fixou na memória nacional não foi apenas pelo sucesso de seu projeto de 'fazer seu nome' ou, dito de outro modo, seu projeto de muito pouco valeria se a memória que procurou criar de si não encontrasse eco na memória coletiva, social. Dessa forma, seu projeto foi vitorioso porque ao criar-se como 'brasileiro', sua voz ressoava junto ao projeto nacional, garantindo-lhe posição de destaque perpetua entre os nomes ilustres do país.

Vale ressaltar que o projeto nacional de falamos não é necessariamente, ou exclusivamente, o imperial. Também no desenvolvimento e consolidação do projeto republicano Gonçalves Dias vai ter seu lugar de brasileiro por excelência garantido, prova disso é que em 1937, será publicado um esboço biográfico seu - sob o título de "Minha terra tem palmeiras..." - na revista Mundo Infantil publicação, que como o próprio nome indicava, estava dedicada ao público infantil. 
No artigo os versos de Canção do Exílio que o serviam de título eram apresentados como "Este verso delicioso, um dos mais deliciosamente brasileiros que cantam aos nossos ouvidos..." ${ }^{\prime 4}$. Seguia-se então uma breve explanação sobre a vida e os trabalhos do poeta. Breve mas pouco econômica em elogios ao "poeta genial, amante de sua Pátria e de sua gente" $"$ e que terminava por afirmar:

Mas, para todos nós, brasileiros, todos nós que temos a idéia doce da Pátria em nossos corações e o seu nome constantemente em nossos lábios, Gonçalves Dias ha de ser sempre o poeta fascinador daquelles versos que cantavam assim:

Minha terra tem palmeiras

Onde canta o sabiá;

As aves que aqui gorgeiam,

Não gorgeiam como lá... ${ }^{48}$

Gonçalves Dias era assim, em fins dos anos de 1930, pouco mais de um século após seu nascimento, exaltado como o brasileiro quase ideal, modelo que se não servisse de estimulo e imitação aos demais, especialmente aos mais jovens, deveria ao menos, ser lembrado como referência identitária.

Nesse sentido é interessante notar que sua imagem foi sendo criada e recriada nas tramas que configuraram aquilo que veio a ser entendido como identidade brasileira. Se em um momento inicial ele mesmo lançou as bases dessa apropriação, dizendo que nascera junto com a pátria, o movimento que se seguiu foi muito maior que ele, e seus biógrafos se encarregaram de fixá-lo no panteon nacional e a 'memória coletiva' acabou por eternizá-lo.

Marisa Lajolo, por exemplo, que desenvolve trabalho onde o poeta maranhense serve de eixo para se pensar a profissionalização do escritor brasileiro no século XIX vai lembrar que

Livros escolares, por exemplo, gostam de frisar que o poeta nasceu no mesmo ano em que a província do Maranhão (de forte influencia portuguesa) reconhece a independência do Brasil.

Confirmando o que parece ser lido como uma predisposição astrológica de Gonçalves Dias para a expressão de sentimento patriótico, outros 
textos apontam (corretamente) que ele era filho do branco João Manuel Gonçalves Dias, português, e deVicência Mendes Ferreira, mestiça de índio e negro. Ou seja, o poeta sai dessas biografias com uma vida sob medida para alimentar interpretações bem intencionadas de coincidências: sua mestiçagem e o ano de seu nascimento não poucas vezes são convocados para explicar a gênese de certas passagens de sua poesia, como o saudosismo patriótico da Canção do exílio ou o lamento épico do Canto do Piaga.

Ao fim e ao cabo, tais leituras endossam, com menos ou com mais satisfação, a velha e ingênua idéia de que vida e obra constituem espelhos límpidos, cristalinos, sem distorções. ${ }^{49}$

\section{Nas biografias, a consolidação de uma memória}

Morto em novembro de 1864, num naufrágio em que foi a única vítima, Gonçalves Dias vai ser objeto de inúmeras biografias, tanto no século XIX, em especial após sua morte, como ao longo do século XX. Não é nosso interesse aqui identificar quantas são essas obras, a bem da verdade, este seria um trabalho quase impossível dada a proliferação de esboços biográficos seus que saíram especialmente ao longo do século passado ${ }^{50}$.

Nesse cenário de vastidão biográfica não há, no entanto, muitas novidades, mas sim uma constante proliferação e repetição de imagens que, como ponderou Marisa Lajolo, buscavam traçar um paralelo entre a vida do homem e a obra, numa constante fixação da imagem de Gonçalves Dias como 'o poeta do Brasil'.

A nosso ver, contudo, essa fixação foi iniciada pelas obras de quatro autores específicos: Joaquim Manuel de Macedo, Antonio Henriques Leal, Lucia Miguel Pereira e Manuel Bandeira. Cada um desses autores e de suas respectivas obras possui características específicas que ajudaram ou a manter e reforçar a memória de Gonçalves Dias que o próprio poeta havia forjado ou a criar/identificar novos valores que ajudaram a consolidar a figura do poeta no imaginário nacional.

Para Marcia de Almeida Gonçalves as biografias no século XIX, mais do que um instrumento para lembrar quem não deveria ser esquecido, apresentavam o exercício de como lembrar. Numa tentativa de amenizar a fugacidade 
da condição humana, conceitos como os de gênio e herói ajudaram a nortear narrativas biográficas que tinham como objetivo construir a memória e a identidade nacional. ${ }^{51}$

Nas palavras da autora, "nas galerias de brasileiros e brasileiras distintos e ilustres, elegeram-se os indivíduos cujas vidas em seus sentidos e realizações deveriam confundir-se com os da própria nação" 52 , possibilitando assim que se efetivassem as estratégias da 'expansão para dentro" ${ }^{53}$ través da criação de 'retratos em papel e letras ${ }^{54}$ daqueles que deveriam ser louvados e servir de exemplo a outros diletos filhos da pátria.

Nesse cenário de criação de identidade nacional, Joaquim Manuel de Macedo e Antonio Henriques Leal foram dois dos autores que investiram na escrita de biografias que formavam verdadeiras 'galerias de brasileiros ilustres'. Macedo vai ser o autor do Anno Biographico Brazileiro ${ }^{55}$, publicado em 1876, para a participação do Brasil na Exposição Internacional da Filadélfia ${ }^{56}$, naquele mesmo ano e Henriques Leal publicará entre 1873 e 1875 seu Pantheon Maranhense: ensaios biográficos dos maranhenses ilustres já falecidos ${ }^{57}$.

Em ambas as obras Gonçalves Dias será figura de destaque, sendo apresentado como o 'gênio' que tornou verdadeiramente 'nacional' a nossa poesia. Nelas seus autores fizeram questão de demarcar justamente os dois pontos que o próprio Gonçalves Dias mais ressaltara de sua memória, a relação do seu nascimento com o da pátria e o a perspectiva de que havia sido ele o inaugurador da literatura brasileira, como havia indicado o elogio que recebera de Alexandre Herculano:

Nascia Gonçalves Dias com a nossa pátria, como Camões desaparecera com a sua; e se Deus, na sua piedade, manda gênios sumos às nações que têm de morrer para lhes alumiar a sepultura, como pondera o Sr. Alexandre Herculano, também os envia para realçar o formoso incunábulo daquelas que surgem entre fulgores. ${ }^{58}$

O inspirado chegou ao termo da sua missão; mas deixou em sua passagem um rasto de luz que nunca se há de apagar; deixou um nome que é uma gloria do Brazil, deixou-nos livros que hão de atravessar os séculos, e uma influencia real, vivificadora e potente, que dará lustre e espirito verdadeiramente nacional á nossa litteratura. ${ }^{59}$ 
Essas imagens fixadas em letras pareciam querer reverberar a memória que já existia, reservando-lhe lugar de destaque eterno no campo das letras nacionais. Nas palavras de Marcia Gonçalves,

Era como se o nascimento e a trajetória da unidade indivíduo devesse, em sentindo, confundir-se com a unidade da nação. No plano da consciência de si e do outro, tais enunciações criavam lugar para cada um e para todos, e, mais, constituíam um referente no nome que designava a coletividade de cidadãos brasileiros. ${ }^{60}$

Mas se o século XIX, com um Brasil recém independente e uma união territorial e política consolidada à custa de muitas disputas e conflitos - intelectuais ou não - fora o momento de construção da identidade nacional, o século XX chegava com um novo regime político, novas tensões e debates e a necessidade latente de se (re)criar essa identidade, afinal, o que era 'ser brasileiro?'

Nesse contexto a chamada biografia moderna, renovada em seus objetos, métodos e estratégias narrativas, vai servir de espaço para a renovação da escrita da história nacional, através da 'humanização' de seus personagens. Nas palavras de Marcia Gonçalves

Se a história, enquanto conhecimento disciplinar era, por excelência, um instrumento basilar na edificação da identidade nacional, a discussão de como ela deveria ser escrita, e de que sujeitos deveriam protagonizá-la - os indivíduos, os grupos, ou as forças sociais -, acabava por cruzar com o debate sobre quem de fato construía ou havia construído a nação. Nesse cruzamento tenso, o lugar do texto biográfico era buscado e, por vezes, entendido como a panacéia que poderia resolver tantos impasses. ${ }^{61}$

Entre os autores que tentaram resolver esses impasses, Lúcia Miguel Pereira, biógrafa de Machado de Assis e de Gonçalves Dias, vai ganhar destaque. Sua biografia do poeta maranhense vai servir para destacar uma imagem sua que acabará por consolidá-lo de vez no modelo de brasileiro autentico, pois Lúcia fará questão de destacar sua origem de mestiço. Se antes ele era 
brasileiro porque nascera junto com a pátria, porque fora o responsável pela independência de nossa literatura, agora, em 1943, ano de publicação da biografia, ele era brasileiro, sobretudo, porque era filho das três raças, porque carregava em si o sangue de negros, índios e portugueses:

Foi o fato de ser lusitano o pai, e filha da terra a mãe, que tornou tão importante a data do seu nascimento. Que de algum modo imprimiu um carater simbólico ao primeiro grande poeta do Brasil; que pôs uma misteriosa identidade entre o seu destino e o do país. Essa identidade, que Gonçalves Dias não proclamou nunca e talvez nunca tenha chegado a sentir nitidamente, foi entretanto nele uma poderosa força subconciente. ${ }^{62}$

Estava traçado assim o perfil de Gonçalves Dias que ele próprio forjara e que seus biógrafos cuidadosamente cuidaram de reafirmar. Era brasileiro, nascera com a pátria e era na sua origem mestiço como ela. O que faltava a essa memória, a essa identidade? Apenas a celebração de sua obra e Manuel Bandeira é quem vai se encarregar de proclamar essa memória.

Ao escrever Poesia e vida de Gonçalves Dias, publicado em 1962, Manuel Bandeira não está preocupado em pormenorizar a vida do poeta, aliás, mais do que uma narrativa de vida, sua obra é, antes de tudo, uma análise literária onde está sendo evocada a qualidade literária do poeta maranhense, qualidade que o destaca no cenário das letras nacionais. Aqui Gonçalves Dias não apenas o iniciador da literatura brasileira, é seu poeta supremo, e Canção do exílio, teria bastado para alçá-lo a esse posto:

Quanto à "Canção do exílio", foi ela sem dúvida o seu primeiro grande momento de inspiração. Ainda que não tivesse escrito mais nada, ficaria, por ela, o seu nome gravado para sempre no coração e na memória da sua gente. José Veríssimo louvou-lhe a simplicidade "quase sublime". Porque o "quase"? A ausencia de qualificativos, a boa escolha dos substantivos concorrem grandemente para o efeito de simplicidade; o encadeamento, o paralelismo reforçaram no seu ar como que largado o sentimento de funda e sossegada, de quase religiosa nostalgia. É verdadeiramente sublime. ${ }^{63}$ 
Antonio Candido em seu célebre estudo sobre a gênese da literatura nacional vai afirmar - surpreendentemente sobre I-Juca Pirama e não sobre a Canção do exílio - que "é dessas coisas indiscutidas, que se incorporam ao orgulho nacional e à própria representação da pátria, como a magnitude do Amazonas, o grito do Ipiranga ou as cores verde e amarela" ${ }^{64}$. Digamos surpreendentemente não em desmerecimento de I-Juca Pirama, mas parece claro que Canção do exílio tornou-se muito mais célebre, incessantemente repetida e incorporada ao imaginário nacional do que o 'canto de morte do filho do norte'. Se ainda hoje vemos referencias à Canção do exílio surgirem aqui e acolá, seja repetindo-a ou parafraseando-la é porque estes versos se incutiram de tal forma no imaginário nacional que é como se sempre tivessem existido, como se não fosse necessário pensar sobre as especificidades de sua produção e circulação, sua força nacional está dada, como está dado que as cores verde e amarela representam o Brasil, como apontou Antonio Candido. Mas não foram essas cores também fruto de escolhas e debates?

Assim, Gonçalves Dias 'é' o poeta nacional. Mas o é porque era esse o seu projeto e porque a construção que fez de si, de sua identidade, encontrou eco e espaço na memória coletiva que se criava, de alguma forma ele de fato nasceu junto com sua pátria, não porque veio ao mundo junto com a consolidação da independência, mas porque criou sua identidade ao mesmo tempo em que se forjava a identidade nacional. 
Notas e Referências

1 Manuel Salgado GUIMARÃES. "Do litoral para o interior: Capistrano de Abreu e a escrita da história oitocentista". In: José Murilo de CARVALHO; Lúcia M. Bastos Pereira das NEVES (Org.). Repensando o Brasil do oitocentos: cidadania, política e liberdade. Rio de Janeiro: Civilização Brasileira, 2009, p. 270.

2 Manuel Salgado GUIMARÃES. Idem, p. 271.

3 Maria Helena ROUANET. "Nacionalismo”. In: José Luís JOBIM (org.). Introdução ao romantismo. Rio de Janeiro: EdUERJ, 1999, pp. 22-23.

4 Segundo a datação publicada nos Primeiros Cantos.

5 Cf. Lúcia Miguel PEREIRA. A vida de Gonçalves Dias. Rio de Janeiro: José Olympio, 1943.

6 A. Gonçalves DIAS. Primeiros Cantos. Rio de Janeiro: Laemmert, 1846. Disponível em Brasiliana Digital: http://www.brasiliana.usp.br/bbd/handle/1918/00634200. Acesso em 26 jun 2010, p. 09.

7 As palmeiras normalmente conhecidas com palmeiras imperiais aqui no Brasil são, na verdade, nativas de outros países do continente americano, como Venezuela e Honduras e foram introduzidas no Brasil por D. João quando da criação do Jardim Botânico, no início do século XIX.

8 A. Gonçalves DIAS apud Lúcia Miguel PEREIRA. A vida de Gonçalves Dias. Rio de Janeiro: José Olympio, 1943, p. 09.

9 Joël CANDAU. Memória e identidade. São Paulo: Contexto, 2011, p. 66.

10 Idem, ibdem.

11 Idem, p. 71.

12 Idem, ibdem.

13 Lúcia Miguel PEREIRA. A vida de Gonçalves Dias. Rio de Janeiro: José Olympio, 1943, p.09.

14 Idem, ibdem.

15 Marcia de Almeida GONÇALVES. Em terreno movediço: biografia e história na obra de Otávio Tarquínio de Sousa. Rio de Janeiro: EdUERJ, 2009, p. 428.

16 Joël CANDAU. Memória e identidade. São Paulo: Contexto, 2011, p. 74.

17 Gilberto VELHO. Projeto e metamorfose: antropologia das sociedades complexas. Rio de Janeiro: Zahar, 1994, p. 47. 
18 No original o poeta cita primeiro as palavras em italiano de Manzoni "Glória! il mio destino è d'agonarla / E o de morir, senza avere gustata" - para, em seguida, traduzi-las. Aqui optamos por apresentar diretamente a tradução.

19 CORRESPONDENCIA ativa de Gonçalves Dias. Anais da Biblioteca Nacional, Rio de Janeiro, v.84, 1964. (impressão de 1971), p. 37-8.

20 Lúcia Miguel PEREIRA. A vida de Gonçalves Dias. Rio de Janeiro: José Olympio, 1943.

21 Idem, p.39.

22 Cf. Manuel BANDEIRA. Poesia e vida de Gonçalves Dias. São Paulo: Editora das Américas, 1962.

23 CORRESPONDENCIA ativa de Gonçalves Dias. Anais da Biblioteca Nacional, Rio de Janeiro, v.84, 1964. (impressão de 1971), p.48.

24 Ambos haviam sido seus condiscípulos em Coimbra e estavam vivendo a essa época em Pernambuco, sendo que Mamede depois de formado em engenharia estabelecera-se em Recife onde sua família tinha influência política.

25 CORRESPONDENCIA ativa de Gonçalves Dias. Anais da Biblioteca Nacional, Rio de Janeiro, v.84, 1964. (impressão de 1971), p.47.

26 Marco MOREL. "Nação e revolução: o rubro veio historiográfico no Brasil na primeira metade do século XIX”. In: CHAVES, Cláudia Maria das Graças; SILVEIRA, Marco Antonio (Org). Território, conflito e identidade. Belo Horizonte: Argvmentvm, 2007, p. 165-6.

27 Idem, p. 174.

28 "Digo que sou Poeta e Doido, mas doido que não tem manias de meter mêdo, e poeta que não é de todo esquecido; a prova de que sou doido é que sou um sem cuidados, e a prova de que sou Poeta é que estou no Rio. Isto quer dizer que um Poeta sem cuidados é igual a um doido com muitos cuidados." Grifos no original. CORRESPONDENCIA ativa de Gonçalves Dias. Anais da Biblioteca Nacional, Rio de Janeiro, v.84, 1964. (impressão de 1971), p.56.

29 CORRESPONDENCIA ativa de Gonçalves Dias. Anais da Biblioteca Nacional, Rio de Janeiro, v.84, 1964. (impressão de 1971), p. 75.

30 Idem, pp. 47-8.

31 HerCUlANO in DIAS, A. Gonçalves. Poesia e prosa completas. Rio de Janeiro: Nova Aguilar, 1998, pp. 98-9.

32 Idem, pp. 99-100. 
33 José Henrique de P. BORRALHO. A Athenas equinocial: a fundação de um Maranhão no Império brasileiro. 2009. Tese (doutorado em História) Departamento de História, Universidade Federal Fluminense, Niterói, 2009, p. 208.

34 A. Gonçalves DIAS. Cantos: collecção de poezias. Leipzig: F. A. Brockhaus, 1857. Disponível em Brasiliana Digital: http://www.brasiliana.usp.br/bbd/ handle/1918/00647200. Acesso em 26 jun 2010 p. VII.

35 Joël CANDAU. Memória e identidade. São Paulo: Contexto, 2011, p. 69.

36 Segundo as datações deixadas pelo próprio poeta na obra.

37 Antônio CÂNDIDO. Formação da literatura brasileira. Belo Horizonte: Itatiaia, 1993.v.2.

38 A. Gonçalves DIAS. Poesia e prosa completas. Rio de Janeiro: Nova Aguilar, 1998, p. 725

39 Idem, ibdem.

40 Idem, p. 726.

41 HERCULANO in DIAS, A. Goncalves. Poesia e prosa completas. Rio de Janeiro: Nova Aguilar, 1998, p. 727.

42 Grifo nosso.

43 CORRESPONDENCIA ativa de Gonçalves Dias. Anais da Biblioteca Nacional, Rio de Janeiro, v.84, 1964. (impressão de 1971), p. 71.

44 Wilton José MARQUES. “O poeta e o poder: favores e afrontas”. In: Estudos históricos, Rio de Janeiro, n.32, 2003, p.266.

45 Joël CANDAU. Memória e identidade. São Paulo: Contexto, 2011, p. 77

46 Mundo Infantil. 1937, p. 15

47 Idem, ibdem.

48 Id., ibdem.

49 Marisa LAJOLO. "O preço da leitura: Gonçalves Dias e a profissionalização de um escritor brasileiro oitocentista". In: Márcia ABREU; Nelson SCHAPOCHNIK (Org). Cultura letrada no Brasil: objetos e praticas. São Paulo, SP: Fapesp, 2005, pp. 61-2.

50 Uma rápida consulta em um site que reúne sebos virtuais apresenta uma imensa lista de livros e revistas onde encontramos biografias do poeta em coleções semelhantes às vidas dos grandes brasileiros ou vida de brasileiros ilustres.

51 Marcia de Almeida GONÇALVES. Em terreno movediço: biografia e história na obra de Otávio Tarquínio de Sousa. Rio de Janeiro: EdUERJ, 2009, p. 454. 
52 Marcia de Almeida GONÇALVES. "Histórias de gênios e heróis: indivíduo e nação no Romantismo brasileiro". In: Keila GRINBERG; Ricardo SALLES (Org.). O Brasil imperial 1831-1889. v.2. Rio de Janeiro: Civilização Brasileira, 2009, p. 454.

53 Expressão cunhada por Ilmar Mattos no artigo "Construtores e herdeiros: a trama dos interesses na construção da unidade política" publicado no Almanack Braziliense em maio de 2005 e recuperada aqui a partir do texto de Marcia de Almeida GONÇALVES. "Histórias de gênios e heróis: indivíduo e nação no Romantismo brasileiro". In: Keila GRINBERG;, Ricardo SALLES (Org.). O Brasil imperial 1831-1889. v.2. Rio de Janeiro: Civilização Brasileira, 2009.

54 Expressão cunhada por Marcia de Almeida Gonçalves para se referir as biografias num contexto de construção do imaginário nacional e que dá título ao projeto de pesquisa coordenado por ela na UERJ no qual atuei como bolsista PIBIC e no qual atuo hoje como pesquisadora.

55 O Anno Biographico é composto de três tomos que compreendem os meses de janeiro a abril, maio a agosto e setembro a dezembro, respectivamente, constitui-se em uma espécie de calendário cívico em que para cada dia do ano Macedo elegeu um indivíduo que, segundo seus critérios, merecia destaque, contando assim com 365 biografias num total. Estes indivíduos eram homens e mulheres selecionados desde os tempos coloniais à contemporaneidade do autor. As disposições das biografias seguiam em geral o dia de nascimento ou morte do biografado (ainda que a data fosse suposta ou inexata), mas em alguns casos o próprio autor declara que foram escolhas feitas de maneira aleatória.

56 No que diz respeito a considerações sobre o Anno Biographico e também sobre os usos do biográfico em geral, foram fundamentais para a elucidação e o levantamento de questões as reuniões de pesquisa do projeto Historias de Gênios e Herói individuo e nação nas narrativas biográficas ao Império do Brasil coordenado pela Prof ${ }^{a}$. Dra . Marcia de Almeida Gonçalves e no qual atuo como pesquisadora.

57 O Pantheon está originalmente dividido em quatro tomos publicados entre 1873 e 1875 pela Imprensa Nacional de Lisboa que contem ao todo 19 biografias distribuídas da seguinte forma: 5 no primeiro tomo; 10 no segundo; 3 no quarto; sendo o terceiro tomo integralmente dedicado a Gonçalves Dias. 
A ordem de publicação original é: tomo I, em 1873; tomos II e III, em 1874; e tomo IV, em 1875. Aqui trabalhamos com a segunda edição, publicada em 1987, e que se encontra dividida em dois tomos, cada um deles reunindo o conteúdo integral de dois tomos da primeira edição, por isso a apresentação, nas referências, como tomo 1 e 2 .

58 Antônio Henriques LEAL. Pantheon maranhense: ensaios biográficos dos maranhenses ilustres já falecidos, t.1. 2.ed. Rio de Janeiro: Editorial Alhambra, 1987, p. 09.

59 Joaquim Manuel de MACEDO. "Discurso". RIHGB, Rio de Janeiro, t.27, 1864, p. 416.

60 Marcia de Almeida GONÇALVES. "Histórias de gênios e heróis: indivíduo e nação no Romantismo brasileiro". In: Keila GRINBERG;, Ricardo SALLES (Org).. O Brasil imperial 1831-1889. v.2. Rio de Janeiro: Civilização Brasileira, 2009, p. 429.

61 Idem, p.128.

62 Lúcia Miguel PEREIRA. A vida de Gonçalves Dias. Rio de Janeiro: José Olympio, 1943, p. 10.

63 Manuel BANDEIRA. Poesia e vida de Gonçalves Dias. São Paulo:Editora das Américas,1962, p. 24-5.

64 Antônio CÂNDIDO. Formação da literatura brasileira. Belo Horizonte: Itatiaia, 1993.v.2, p.85. 